\title{
A systemic evaluation of Advisory Services to Family Farms in West Africa
}

\author{
Auteurs \\ Guy Faure, CIRAD, UMR Innovation, 79 rue Jean-François Breton, TA 60/15, 34398 \\ Montpellier cedex 5, tel 04676165 87,guy.faure@cirad.fr \\ Pierre Rebuffel, CIRAD, UMR Innovation, pierre .rebuffel@cirad.fr \\ Dominique Violas, GRET, violas@gret.org
}

\begin{abstract}
:
The objective of this communication is to show that the functioning of Agricultural Advisory Services (AAS) is strongly determined by the financing and governance mechanisms put in place, the quality of human resources available for its implementation, and characteristics of the advisory method used.

The analysis of the development process of two Advisory Services to Family Farms (ASFF) in West Africa shows that (i) financing mechanisms are defining governance rules (ii) governance mechanisms reveal social relationship among stakeholders and influence the content of advisory provision, (iii) the quality of the advise is closely related to extension agents skills and staff members skills, and (iv) there is a need for permanent adaptation of the advisory method depending on the changing financing funding capacities and human resources availability.
\end{abstract}

\section{From Agricultural extension to Family farm advice}

In West Africa the organization of AAS is deeply changing. After a withdrawal of the state from agricultural extension functions and a stop of "Training and Visit" programs financed by the World Bank, we are witnessing the emergence of initiatives supported by farmers' organizations, NGOs, agro-industries, input suppliers, etc... (Swanson 2008).

Those initiatives developing an Advisory Services to Family Farms (ASFF) have benefited from methodological and financial support from French Cooperation. Based on common principles several experiences have been carried out, including in Burkina Faso and in Benin (Faure et al., 2004). However, despite the positive impact of theses initiatives on family farm performances, their sustainability is not guaranteed and still depends on external aid.

The aim of this communication is to show that the structuring and the development of an AAS are not linear processes and that the characteristics of the advisory system is the result of a balance between its source of financing, its governance mechanisms, the quality of field staff, and the method used to deliver advice. The study is based on the analysis of two situations (Benin and Burkina Faso) in the framework of an action-research approach.

\section{The conceptual framework}

The concept of "Advisory System" (Birner et al., 2006) will be used to analyze the development process of the two AAS. An advisory System is formed of three components:

(1) the advisory method, including its scope (technical or economic, production or marketing, tactical or strategic, etc.) and its intervention modalities (advisory tools, type of relationship between adviser and farmer); 
(2) the stakeholders of the advisory system including a providers subsystem (service supply) and a users subsystem (service demand) both of them taking into account the human resources dimension (skills, training);

(3) the functional relationships between system components to understand their interdependence highlighting two main points which are the financing and the governance.

Figure 1: The advisory system

Source: authors adapted Gadrey 1994

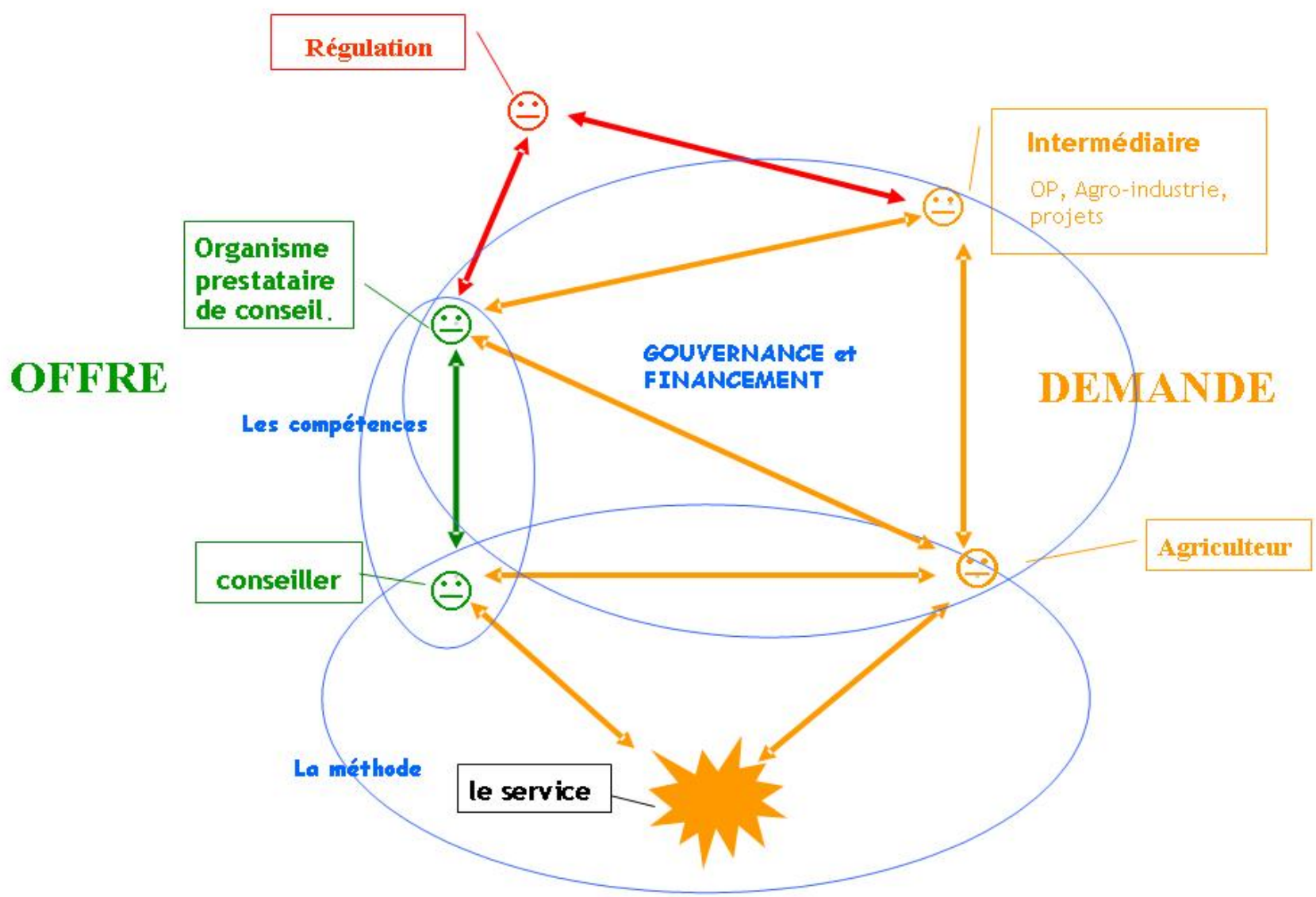

This representation gives a framework to identify the balance status between the different components of the Advisory system. Therefore, blocking in the AAS development can be interpreted as an imbalance between available funding, governance mechanisms, field agents' skills and method implemented.

\section{Case studies}

\section{ASFF in Benin}

On funding from the French aid and with the support of development projects, the ASFF was implemented in Benin in three phases.

\section{An experimental phase}

A pilot phase started in 1995. The establishment of a "farm management centre" at the Agricultural Sciences Faculty gave the opportunity to design and test the method prototype. Logbooks on farm management practises were designed and distributed to pineapple producers in southern Benin. Logbooks where designed for literate famers. At this stage, emphasis was put on cash flow monitoring. The method was considered elitist 
and top-down by farmers who received little feedback to improve the management of their farms.

\section{A ASFF controlled by NGOs}

To overcome this difficulty, from 1997 until 2000, the implementation of the ASFF was entrusted to four NGOs whose executives were former students of the Agricultural Sciences Faculty. Closer to farmers and highly reactive, these NGOs worked with groups of young volunteer farmers, producers of pineapple, cotton, or rice. These NGOs adapted the advisory method to farmers needs including new themes.

\section{A development which involve more farmers}

To support extension up of ASFF in new regions, NGOs and the development project decided in 2000 to translate all ASFF tools in national languages. With the support of the NGOs, the first members, often literate in their own national language, adapted the logbooks and formed new groups in their villages. Thus, farmer-advisors were trained and supported by NGOs advisor to address simple issues with other farmers. At this stage Farmers Organisations (FO) also launched their ASFF.

Nowadays, 4 NGOs and 2 FOs provide ASFF to 5000 farmers in Benin with a total of fifty advisors and 500 farmer-advisors.

\section{A deadlock due to funding}

However, despite their interest in the process neither farmers nor FOs contribute significantly to the running cost of the service which remains supported by the external aid. Financing becomes a blocking factor for the development of the ASFF, which greatly weaken its durability. Funding opportunities are envisaged, with a possible involvement of AICB (Cotton Stakeholders Association in Benin) in the cotton areas of the country. If this support concretize, it would initiate a new cycle of evolution of the ASFF.

\subsection{ASFF in Burkina}

The development of the ASFF in Burkina Faso also passed through different phases.

\section{A test phase with a strong involvement of research}

From 1993 to 1995, on request of the NAES (National Agricultural Extension Service), agricultural research developed and tested in three villages a new method of advice to family farms (Faure et al., 1998). However, it was never implemented on a large scale because of disengagement of NAES from agricultural extension.

\section{An attempt of a FO to develop a ASFF}

In 1998 UNPC-B (National Cotton Farmers organisation) wishes to engage in the establishment of an advisory service to family farms taking into account all the farm activities (Rebuffel and Faure, 1999).

UNPC-B encountered two main difficulties in the implementation of this project:

$\Rightarrow$ On the one hand it was difficult to identify experienced field staff with technical and human skills required by FO.

$\Rightarrow$ On the other hand, UNPC-B faced an opposition from donors supporting cotton sector. For them the establishment of an ASFF would have come into conflict with the extension service of the cotton company. Without self-financing capacity, UNPC-B stopped the implementation of this project. 


\section{A willingness of the cotton company to promote ASFF}

Starting from 2000, the cotton company saw the AFF method, as a tool that may help to improve cotton production and to improve its relations with farmers. With the methodological support of research, a test was initiated. During this phase two major limitations were underlined by the cotton company: (i) the small number of producers who can be supported by an advisor, (ii) the heavy workload that represents the implementation of the AFF for field staff who have other functions. During this pilot phase, UNPC-B was gradually involved in a formal co-piloting of the service. However, the different committees involving representatives of the two structures didn't work, mainly for lack of involvement of UNPC-B, reflecting its disagreement over the orientations of an advisory service implemented by cotton company staff.

\section{The interactions between components of the advisory system}

To understand the development process how these two advisory systems, it is important to take into account the interactions between their components.

\section{The kind advisory method implemented depends on financial and human resources availability}

Method and tools used in Benin and Burkina Faso are related. However, in Benin the emphasis is put on farmers training and farm economic analysis. In Burkina, emphasis is put on farmers training for technical and economic analysis of their farming system.

In both situations, the method was designed during a small scale pilot phase, which strongly determined the characteristics of devices which were developed during the up scaling phase. It predefined: (i) the advisors profile as being able to master farm management tools, animation techniques, etc.., (ii) advisors work organisation (number of farmers groups, group size, etc..). Therefore, the running cost per participant was relatively high.

In Benin, the method subsequently evolved. This didn't come from new needs expressed by farmers as they didn't have formal way to influence the planning and evaluation of NGO activities. It was more the result of donors' will to increase the number of participants while controlling expenditures, combined with NGOs willingness to preserve their advisors networks and their skill level. The main innovation was the implementation of a farmersadvisors network supported by formal advisors. Such a modification required to deeply review the organization of training activities and tools to adapt them to farmers-advisors' skill and availability and to the new role of formal advisors.

\section{Nature and quality of advice are closely related to advisors' skills}

Advisors profiles are different in Benin and Burkina. In Benin, during their initial A levels training, advisors trained for farm management. In Burkina, most of the advisors of the cotton company have a Master degree in agriculture, giving them technical skill in many areas.

Training level and origin of the advisor have an influence on the content and quality of advice, as well as the type of relationship established with the farmer.

A high level of qualification is often synonymous of relevant advice, which can be specialized or global, including a strategic dimension, but also of a poor relationship with the farmers.

Lower levels of qualification often limit the advice to specific technical areas. A farmeradvisor, according to their experience, can only deal with certain themes, in a process closer to animation than to advice. In Benin, the decision to rely on farmer-advisors resulted in a deep reviewing of advisory tools and advisors work-organization. 


\section{Governance influences the content of the board and management advisors}

In Benin, governance is based on two set of contracts: (i) the first set between a project and private advice providers, (ii) the second set between these providers and farmers. FOs are not involved in planning and evaluation of activities at regional and national level.

In Burkina, at national level, governance is shared between the cotton company and the cotton farmers organisation. But at lower levels, no mechanism has yet been implemented to define and monitor advisors work.

The governance arrangements have a strong influence on the content of the advice. This influence may be through explicit mechanisms to take into account the demands of the stakeholders (steering committees at local or national level, contracts with providers...). This influence can also be implicit through power relationship among stakeholder of a same agricultural system.

\section{Financing mechanisms are crucial in defining advice content and governance rules}

The two case studies show that the stakeholders face the same challenge. Initially it is international cooperation funding which helped to develop the method and to initiate a first phase of development.

In Benin, farmers' financial contribution is symbolic way the council and FOs are not contributing. Thus, prospects focus on access to state and cotton sector subsidies.

In Burkina, the institutional affiliation of the ASFF offers hope of financing through taxes on cotton marketing and state subsidies.

The budget available have a direct impact on (i) recruitment of advisors, through the definition of their profiles, their salary and their number, and (ii) the advice method, through the intensity and quality of the relationship between advisors and farmers and therefore the ratio of farmers per advisor.

But also, those who finance the ASFF want to promote their interests or their views. Thus, in Burkina Faso, the cotton companies which support a significant percentage of running costs, which to promote advice contents that strengthen cotton production.

\section{Conclusion}

Analysis of ASFF in Benin and Burkina Faso shows strong interactions between the different components of an advisory system (methods, staff skills, governance, and financing). These components interact over time alternating balance and reorganization phases, expansion and lock-up phases. The complexity of the dynamics observed highlight that promotion ASFF does not follow a single pattern but that the ASFF are socially constructed as reflect of stakeholders strategies in a specific context.

Supporting establishment or strengthening of ASFF requires to take into account interactions between components of the system and to rule out standard solutions.

Support should lie on strengthening the stakeholder capacity to anticipate blocking situations through understanding consequences of a decision on each component of the system.

However, to avoid deadlocks it is suggested to involve stakeholders beyond a specific commodity sector to establish sustainable funding.

\section{Bibliography}

Birner R., K. Davis, J. Pender, E. Nkonya, Anandajayasekeram P., J. Ekboir, Mbabu A., D. Spielman, D. Horna, Benin S., Cohen M. (2006) From best practice to best fit. A framework for analyzing pluralistic agricultural advisory services worldwide, Washington, IFPRI, $121 \mathrm{p}$. 
Faure G., Dugué P., Beauval V. (2004) Conseil à l'exploitation familiale, Expériences en Afrique de l'Ouest et du Centre, GRET-CIRAD, France, $127 \mathrm{p}$.

Faure G., Kleene P., Ouedraogo S. (1998) Le conseil de gestion aux exploitations agricoles dans la zone cotonnière du Burkina Faso : une approche renouvelée de la vulgarisation agricole. In «Gestion des exploitations et des ressources rurales». Etudes et Recherches sur les Systèmes Agraires et le Développement, INRA-SAD, No 31, pp 81-92.

Gadrey J. (1994) Les relations de service dans le secteur marchand. In Bandt J., Gadrey J (eds) Relations de service, marchés de services, Paris, CNRS Editions, pp 23-41

Legile A., Giraudy F. (2005) Mission d'appui au volet conseil de gestion du PADSE, 58 p.

PADSE. (2003) Actes de I'Atelier National sur le Conseil de Gestion, Bohicon, 110 p.

PADSE. (2005) Le conseil de gestion à l'exploitation agricole au Bénin, Cotonou, 65 p.

Rebuffel P., Faure G. (1999) Emergence d'un dispositif de conseil d'exploitation gérée par les organisations paysannes au sein de la filière cotonnière burkinabé. Actes de l'atelier « références technico-économiques et conseil aux exploitations agricoles », 1ER septembre 1999, pp 109-120.

Swanson, B. E. (2008) Global Review of Good Agricultural Extension and Advisory Service Practices, Rome, FAO, $82 \mathrm{p}$. 